\title{
Educação Estatística E Felicidade: Reflexão Sobre Suficiência Para Uma Vida Saudável E Sustentável Para O Planeta
}

\author{
Statistic Education And Happiness: Reflexion About Sufficiency For A Healthy Life \\ And Sustainable For The Planet
}

\author{
Diva Valério Novaes * \\ Instituto Federal de São Paulo (IFSP) - Brasil \\ Vanessa Maciel Mangelot Silva** \\ Instituto Federal de São Paulo (IFSP) - Brasil
}

\begin{abstract}
Resumo
O processo de ensino e aprendizagem, para ser mais efetivo, necessita considerar todas as condições orgânicas, sociais, cognitivas, emocionais e físicas dos estudantes. As escolhas educacionais do presente exigem mudanças em função das alterações que se notam na sociedade e a legislação educacional para Educação Básica, sugere educar para a vida. Com esse entendimento, no âmbito de um grupo de pesquisa, desenvolvemos um projeto intitulado Estatística e Educação Socioemocional, com o objetivo de criar atividades que permitam trabalhar conteúdos curriculares de Estatística e aspectos da Formação Interdimensional de maneira transdisciplinar, aplicar e observar quais habilidades, de conteúdos específicos ou socioemocionais, foram construídas ou beneficiadas com esta escolha didática. Avanços da Neurociência e da Ciência Hedônica, trazem contribuições para o processo educacional, têm interfaces com princípios da Educação Estatística e serviram de base teórica para este trabalho. A metodologia utilizada se deu com metodologia ativa, rodas de conversas, improvisação teatral aplicada à educação e envolvimento dos familiares nas atividades elaboradas. Apresentamos e discutimos uma destas atividades desenvolvida com alunos do $6^{\circ}$ ano da Educação Básica de uma escola privada. Os resultados denotam que os alunos se envolveram de maneira significativa com a atividade, apresentaram bom aproveitamento nos conteúdos de Estatística previsto no plano de ensino e simultaneamente puderam refletir sobre necessidades humanas fundamentais, sem as quais se pode desenvolver patologias e distinguir necessidade de maneiras de satisfazer necessidades, considerando a sustentabilidade ambiental. As respostas apresentadas pelos familiares na pesquisa, propiciou um contraste que ampliou a reflexão dos adolescentes.
\end{abstract}

Palavras-chave: Educação Estatística, Transdisciplinaridade, Neurociência e educação, sustentabilidade.

\begin{abstract}
In order to be effective, the process of teaching and learning, must take into consideration the organic, social, cognitive, emotional and physical conditions of the students. The learning options of the present

\footnotetext{
* Doutora em Educação Matemática pela PUC-SP. Profesora de Estatística e Didática nos Cursos de Mestrado Profissional em Ensino de Ciências e Matemática e Licenciatura em Matemática no IFSP- campus São Paulo, Brasil. diva@,ifsp.edu.br

** Mestranda no Curso de Mestrado Profissional em Ensino de Ciências e Matemática no IFSP - Campus São Paulo, Brasil e professora de Matemática na Educação Básica. mangelot@gmail.com.
} 
require changes, because of what it is possible to notice in the society and the educational law for the basic school education, suggests teaching for everyday life. With this understanding, in a researching kind of view, we developed a project named Statistical and Emotional Skills and its goal is creating activities that allow working the Statistical curricular subjects and the interdimensional development in a transdisciplinary way, applying abilities and watching which of them are being built or which benefit from this teaching choice. The neuroscience and hedonistic sciences advances, bring contributions to the educational process, interface with the Statistical education and are a theoretical basis for this work. The methodology used came with an active methodology, conversations with students, theatrical improvisations applied to the education and the enrollment of family members in the activities. One of the activities was introduced and discussed with the 6th grade students of a private school. The results show that the students were involved in the activity in a strong way, presented a good use of the Statistical content in the lesson plan and could simultaneously reflect on basic human needs and distinguish the different ways of having needs, considering the environment. The answers presented by the family members in the research showed a contrast that made the thinking of those teenagers grow considerably.

Keywords: Statistical Education, Transdisciplinarity, Neuroscience and Education, Sustainability.

\section{Introdução}

Neste artigo, discutimos necessidades de mudanças educacionais evidenciadas na sociedade atual, buscamos contribuições advindas das áreas de Neurociência e Psicologia e em aspectos favoráveis à formação em múltiplas dimensões do ser humano, para um estudo transdisciplinar que envolve a formação estatística e pessoal dos estudantes.

Os princípios da Educação Estatística, têm como base formar cidadãos capazes de compreender o mundo social e natural em que vivem. Dessa forma, esta educação, deve capacitar as pessoas para atuarem eficientemente nos contextos pessoais e profissionais da vida. Segundo Gal (2002), pessoas estatisticamente letradas são capazes de utilizar informações adequadamente, pensar criticamente sobre estas e tomar boas decisões com base nelas. Isso pressupõe uma atitude de questionamento diante de mensagens que podem ser enganosas, desproporcionais, parciais ou incompletas.

A Análise Exploratória de Dados, Batanero (2001), considera que os dados são constituídos de regularidades ou tendências, e desvios e variabilidades. Com forte apoio em representações gráficas, medidas resumo, análise dos valores mínimo e máximo, pontos de concentração e de dispersão nos dados em estudo, pode-se promover análises capazes de fornecer o máximo de informações possíveis com os dados, o que favorece a tomada de decisões responsáveis e permite gerar novas hipóteses para outros estudos. Segundo Moore (2005), a Estatística nos fornece ferramentas e uma linguagem por meio da qual podemos lidar com a incerteza que existe em toda parte.

Os desafios, incertezas e complexidades que a realidade nos coloca exigem novos 
caminhos para a educação. Na área de Gestão de Pessoas, Mussak (2003), Wong (2010), entre outros, afirmam que as pessoas são admitidas no trabalho por suas competências técnicas e demitidas pelo comportamento pessoal. Estes autores descrevem os principais motivos para estas demissões: procrastinação, impontualidade, falta de interesse e criatividade, dificuldades de relacionamentos e de trabalhar em equipe, entre outras. Esse fato segundo estes autores, em parte, se deve a formação pessoal, muitas vezes esquecida na escola. Andrews (2011), relata que a Organização Mundial da Saúde (OMS) estima que até 2020, se nada for feito, a depressão será uma epidemia mundial, podendo se tornar o segundo maior problema de saúde pública no mundo. Berndt (2018), observa que no ambiente profissional de hoje, as pessoas com problemas psíquicos chamam mais a atenção que anteriormente, pois com uma doença psíquica não é possível dar conta das tarefas exigentes em diversas profissões modernas. Muitas profissões do passado não exigiam motivação própria, criatividade e flexibilidade que tantas outras nos dias de hoje exigem.

Os recentes estudos sobre a felicidade, se deve ao fato de que em toda parte as coisas estão dando errado. [...] Temos a sensação de não desfrutar da felicidade como deveríamos e de não a buscar onde deveríamos. Não confiamos nos governos e nem uns nos outros. Motoristas estão se enfurecendo e adolescentes se suicidando, (Andrews, 2011, p.12).

O estudo da felicidade - a ciência hedônica - novo campo de pesquisa científica desde 2002, discute aspectos que podem favorecer o processo educacional. Segundo esses estudos, não é o sucesso quem traz a felicidade, mas é a felicidade quem traz o sucesso Andrews (2011). Esta autora afirma que a busca da felicidade e da satisfação com a vida são critérios centrais para se ter saúde e sucesso na vida.

Segundo Morin (2011), não existe uma maneira de harmonizar completamente o bem individual e o coletivo, assim como de definir uma felicidade coletiva a partir do conjunto de felicidades individuais. A busca de otimização nos problemas humanos ultrapassa todo o potencial de investigação disponível, conclui este autor. Para que pudéssemos nos limitar à elaboração de soluções satisfatórias: as do mal menor, necessitaríamos educar para que os estudantes atuem com equilíbrio nas relações sociais, considerando o $\operatorname{Self}$ (eu aqui e agora), o outro, nós, o ambiente natural e social e a espécie.

Para minimizar os desequilíbrios na saúde e nas relações sociais, como descrito anteriormente, temos agora um duplo compromisso: ensinar conteúdos disciplinares e, ao mesmo tempo e com o mesmo valor, eu diria, ensinar formas de convivência institucional. (Macedo; Bressan, 2016, p.48).

Nota-se a importância da educação escolar se preocupar com esses aspectos na 
Educação Básica, visto que os estudantes permanecem longos anos, por muitas horas o ambiente escolar. Consideramos em nosso grupo de pesquisa, que felicidade pode ser um rico contexto para trabalhar conteúdo específico de ensino e promover reflexões com base em estudos científicos disponíveis para contribuir com a formação pessoal dos alunos. A formação para a vida consta como objetivo da educação básica na legislação educacional brasileira, mas, como apontam Wong (2010), conceituado Hadhanter brasileiro e outros pesquisadores, a formação pessoal é muitas vezes esquecida na escola.

A Lei 9.394/1996 de Diretrizes e Bases da Educação (LDB), em seu Art. 22, aponta que a finalidade da Educação Básica é desenvolver o educando, assegurar-lhe formação comum indispensável para o exercício da cidadania/vida e fornecer-lhes meios para progredir no trabalho, para o aprendizado permanente e para os estudos posteriores. Meios para progredir no trabalho, na Educação Básica, está relacionado com valores, atitudes e procedimentos gerais, como aqueles que evitariam as demissões descritas anteriormente. Preparar para o exercício da cidadania pressupõe o aprendizado para viver na sociedade, considerando a complexidade que ela apresenta. Preparar para estudos posteriores inclui criatividade e protagonismo para lidar com a velocidade das mudanças do mundo contemporâneo. Consta nas Diretrizes Nacionais Curriculares para Educação Básica (2013), que o conceito de qualidade na educação foi se transformando no decorrer das últimas décadas. Entre os anos 70 e 80 estava associada às condições básicas de funcionamento das escolas. Na década de 90 prevaleceram preocupações com o rendimento escolar dos alunos. Nos dias de hoje, outro conceito de qualidade passa a ser gestado: Qualidade social da educação.

Em consonância com a legislação brasileira, o modelo pedagógico do Programa Ensino Integral da Secretaria da Educação do Estado de São Paulo, SESP (2014), propõe a Educação Interdimensional como busca da integração entre as diferentes dimensões constitutivas do ser humano nos processos formativos que vivencia na escola. Segundo as Diretrizes deste programa, isso pressupõe o equilíbrio das relações do indivíduo consigo mesmo, com os outros seres humanos e com a natureza. Nota-se que a legislação reconhece a interferência de problemas sociais e econômicos, no processo de ensino e aprendizagem.

Dessa forma, pode-se observar interrelações entre objetivos educacionais percebidos por várias instâncias da sociedade, explícitos na legislação educacional brasileira e aqueles admitidos como responsabilidade da Educação Estatística. A linguagem da Estatística, Moore (2005), faz com que números e fatos ganhem significado em função do estudo do contexto e pode ser essencial para interpretar o ambiente mutável em que vivemos, reduzindo a 
possibilidade de erros nos processos decisórios com base em dados.

Embora muitos possam compreender a necessidade desta formação integrada, as autoras notam em sua prática, que os alunos do Curso de Formação de Professores em Matemática da instituição em que atuamos, têm dificuldade para fazer essa articulação. No âmbito de um grupo de pesquisa, cadastrado no Conselho Nacional de Desenvolvimento Científico e Tecnológico (CNPq), intitulado Políticas Públicas para a Educação Básica, trabalhamos com alunos do Mestrado Profissional em Ensino de Ciências e Matemática, e, de Licenciatura em Matemática, em um projeto de Estatística e Educação Socioemocional desde 2014. Sob coordenação da primeira autora deste texto, criamos atividades transdisciplinares visando trabalhar os conteúdos de Estatística propostos no plano de ensino e socioemocionais com o mesmo nível de importância. Apresentamos uma destas atividades com discussão didática.

\section{Neurociência E Educação Socioemocional}

A Neurociência, área multidisciplinar, pesquisa o sistema nervoso para entender as bases neurobiológicas do comportamento. Esse conjunto de disciplinas estudam pelos mais variados métodos, o sistema nervoso e as relações entre as funções cerebrais e mentais. Um dos principais objetivos da Neurociência é explicar como a cognição e a consciência humana nascem da atividade do cérebro, Lent (2016).

A Neurociência teve um desenvolvimento acelerado a partir da década de 1990, com o surgimento de novos exames de neuroimagens, que permitiram ver o cérebro em funcionamento. As novas descobertas nesta área se estenderam aos profissionais de outras áreas, entre elas a educação.

O conhecimento da neurociência contribui apenas com uma parte do amplo contexto em que o processo de ensino e aprendizagem ocorre. No entanto, o trabalho do professor pode ser mais significativo e eficiente, quando ele conhece o funcionamento cerebral. Conhecer os períodos mais receptivos para aprendizagem e aproveitá-los de maneira mais eficiente, os mecanismos da atenção e da memória, as relações entre cognição, emoção, motivação e desempenho, entre outras, pode contribuir para melhorar o processo de ensino e aprendizagem, explicam os neurocientistas Cosenza \& Guerra (2011). Estes estudos nos auxiliam a compreender de que maneira as diversas dimensões do ser humano, tais como, corpo físico, emoções e sentimentos não podem ser separados no ambiente escolar.

Algumas contribuições da neurociência para a educação têm base na neuroplasticidade 
e no processo de maturação do cérebro humano. Plasticidade cerebral é a capacidade que o cérebro tem de modificar sua estrutura ante experiências da vida, e assim, possibilitar a aprendizagem. Nosso cérebro é mais plástico na infância e menos plástico conforme envelhecemos. Macedo e Bressan (2016), explicam que os jovens têm momentos em que estão mais propícios a determinadas aprendizagens, denominados "Janelas de oportunidades". Nesses períodos, poderiam aprender conteúdos disciplinares e habilidades de forma mais eficiente.

O processo de maturação do cérebro ocorre de diferentes formas em suas diversas regiões. Na adolescência, as regiões sub corticais ligadas à busca por novidades e prazer estão altamente desenvolvidas e ativas, mas as áreas corticais relacionadas ao controle desses impulsos ainda não estão suficientemente maduras para controlar tais estímulos de forma eficiente. (Macedo; Bressan, 2016, p.25).

Nesse sentido, afirmam esses autores, a neurociência facilita o entendimento da tendência a atitudes imprudentes e tomadas de decisão precipitada dos adolescentes, visto que o amadurecimento das funções executivas superiores, se completa apenas no final da adolescência. $\mathrm{O}$ autocontrole se desenvolve pouco a pouco, e requer ajuda externa, por exemplo, para coordenar prioridades e fazer escolhas saudáveis. Coordenar prioridades é saber esperar, suportar o adiamento de satisfações que não podem ser imediatas. É necessário que a formação ofereça oportunidade de negociar, receber limites, para que não se torne um adulto permissivo. É necessário saber que ganhos implicam perdas, que não é possível escolher ou querer tudo. Nota-se a importância de implementar métodos educacionais que vão além do cognitivo e incluam habilidades socioemocionais. Favorecer o desenvolvimento dos componentes das funções executivas, tais como, controle inibitório, flexibilidade cognitiva, para que o adolescente seja capaz de refletir, tomar decisões, planejar de forma positiva para si mesmo, para seus pares e para a sociedade a que pertence, defendem estes autores.

Segundo Agüerra (2008), nosso cérebro exige quatro recursos para o seu bom funcionamento: atenção, memórias, percepção e consciência, com potenciais e limitações. Esses recursos funcionam de maneira integrada, melhorando um deles, observa-se melhora nos demais. Entre todos estes recursos, o que mais temos condições para melhorar na educação é a atenção.

Estima-se que o cérebro humano processa milhares de bits de informação por segundo, de toda essa informação a consciência consegue processar aproximadamente $2 \%$, não só porque nosso cérebro não tem capacidade para examinar tudo isso, mas também porque não é necessário. Assim, a atenção é o mecanismo do cérebro para selecionar o que é importante e deixar de lado o que é dispensável. O cérebro humano tem motivação intrínseca para aprender, mas está disposto a fazê-lo apenas para aquilo que considera significante. Assim, para os 
professores uma das maneiras de capturar a atenção dos alunos é apresentar os conteúdos a ser ensinados de maneira que estes o reconheçam como importante, Cosenza e Guerra (2011).

A emoção, segundo Damásio (2000) é um conjunto de reações químicas e neurais formando um padrão. Esta nasce da interação entre corpo e cérebro: primeiro ter uma emoção, por exemplo, um tremor nas mãos, um desconforto no estômago, arrepio, lágrimas, em seguida sentir a emoção: medo, prazer, tristeza. Não existe uma expressão verbal para a emoção. $\mathrm{O}$ sentimento é uma interpretação do que foi vivenciado no palco do corpo e nomeado pela consciência. A maneira como um sentimento torna-se conhecido pelo organismo que o sente enfrenta o obstáculo da consciência. Se esta está comprometida, o mesmo se dá com a emoção e sua interpretação: o sentimento. Assim, a consciência pode ser a função biológica crítica que nos permite saber o que é que estamos sentindo, abrir as portas da arte, da ética e da ciência e assegurar não só a nossa sobrevivência, mas todas as criações da vida humana, pondera Damásio (2000).

São considerados sinônimo de felicidade, as palavras prazer, bem-aventurança, êxtase e contentamento, mas nenhuma delas descreve de forma precisa o que pode ser a felicidade. Estas emoções são passageiras, desfrutáveis e importantes, mas não são a medida, ou os pilares da felicidade. Dado que somos todos diferentes, que algum sofrimento é inevitável na vida de qualquer um, que felicidade não é um ponto finito e definível a partir do qual finalizamos nossa busca, pois sempre podemos ser mais felizes, seria muito difícil encontrar uma definição coerente para o que é felicidade. Podemos, no entanto, refletir sobre princípios gerais que sustentam uma vida feliz e gratificante, Ben-Shahar (2018).

Parar de buscar posses materiais e honrarias seria declarar guerra contra a natureza humana, no entanto, dinheiro e prestígio não precisam ser a busca central se compreendemos verdadeiramente quais são nossas reais necessidades essenciais, conclui Tal Ben-Shahar. No que se refere aos estudantes, este autor nota que as crianças aprendem com pais e professores que notas e prêmios são a medida do sucesso, que sua responsabilidade é produzir boletins excelentes. Assim, afogados em trabalhos que não gostam, são motivados pelo medo do fracasso e não incentivados a buscar caminhos que lhes deem prazer e significado. Dessa forma, podem confundir desafios com sofrimento, e mais tarde, transferir essa concepção para o trabalho.

Fluxo, de acordo com Csikszentmihalyi, é um estado no qual se fica imerso numa experiência que por si mesma é gratificante, um estado em que sentimos que somos um só com a experiência, em que ação e gratificação se juntam. [...] Se a dificuldade de uma tarefa é alta e nosso nível de perícia é baixo, então sentimos ansiedade, se nossa perícia é alta e a dificuldade da tarefa é baixa, sentimos aborrecimento. Quando a dificuldade 
da tarefa corresponde ao nível de perícia, experimentamos o estado de fluxo. Tendo em vista que muitos estudantes experimentam aborrecimento ou ansiedade na escola, não tem prazer nem desempenho máximo, (Ben-Shahar 2018, pp.116,118,119).

As crianças internalizam as crenças de seus educadores, mesmo quando estas forem implícitas. Ao enfatizar boas notas, que são tangíveis as escolas reprimem o desenvolvimento emocional das crianças, que poderão ter dificuldade para valorizar necessidades que conduzam a bens intangíveis. Elas aprendem que as gratificações emocionais são secundárias para o tipo de conquistas que os outros podem reconhecer e validar, que as emoções apenas atravancam o caminho para o sucesso, que é melhor suprimi-las. A ironia é que as emoções são necessárias para que se busque a felicidade e para que se consiga sucesso material, argumenta ainda Tal Ben-Shahar, psicólogo da Universidade de Harvard.

Nota-se que todos buscamos a felicidade, mas compreender os complexos processos nos quais essa busca está envolvida, demanda estudo. Avanços da Neurociência nas últimas décadas esclarecem alguns destes processos e outros, facilitadores da aprendizagem. Tais estudos, quebram a separação corpo-mente, entre pensamento, emoção, sentimento e ação, Mores \& Torre (2004).

A Educação Socioemocional é o processo de aquisição ou reforço de habilidades que auxiliam pessoas a lidarem consigo mesmas, a relacionarem-se com os outros e a executarem tarefas de maneira competente e ética. Os pesquisadores do Colaborative for Academic, Social and Emotional Learning - CASEL (2015), descrevem diferentes abordagens desta modalidade de educação, podendo ser oferecida como disciplina a parte, como um projeto de toda a escola, ou ainda, inserida nos contextos educacionais de qualquer uma das disciplinas do currículo escolar de maneira transdisciplinar ou interdisciplinar. No entanto, todas elas convergem para o trabalho de construção de habilidades em cinco aspectos principais:

Autoconhecimento: diz respeito ao reconhecimento das próprias emoções, valores, autoeficácia e limitações. Foca o estudo das emoções primárias e universais: medo, tristeza, raiva, alegria e surpresa ou repugnância.

> Consciência social: ligada ao cuidado e à preocupação com as outras pessoas, assim como com a capacidade de perceber a emoção no outro e aceitar sentimentos diferentes dos seus, apreciar a diversidade e respeitar o próximo.

$>$ Tomada de decisão responsável: conseguir identificar verdadeiros problemas, analisar e refletir sobre a situação, ter habilidades de resolução de problemas por meio de atitudes baseadas em dados, em processos éticos e morais, com fins construtivos. 
Habilidades de relacionamento: com base na formação de parcerias positivas, pautadas pelo compromisso, pela cooperação, pela comunicação efetiva, pela flexibilidade na negociação de acordos, possibilitando que a pessoa lide satisfatoriamente com conflitos que possam surgir, saber solicitar e prover ajuda.

> Autogestão: relacionado à capacidade de autogerenciamento de comportamentos e emoções a fim de atingir uma meta. Orienta a motivação interna e como consequência, a disciplina e a persistência ante desafios. Pode usar para isto, ferramentas como organização, humor e criatividade (Tacla, Norgren, Ferreira, Estanislau \& Fóz 2014).

$\mathrm{Na}$ atividade aqui discutida, buscamos observar se houve contribuição em um ou mais destes aspectos. $\mathrm{O}$ tema central desta atividade é a felicidade e o contexto utilizado para essa discussão foi o das necessidades essenciais do ser humano, segundo a matriz de necessidades essenciais apresentada pelos psicólogos Max-Neef e Hopenhayen (1989), apud O’Sullivan, (2004). Algumas necessidades essenciais do ser humano são tangíveis e outras são intangíveis, essas últimas são de difícil identificação sem formação socioemocional. Justificamos a seguir nossa escolha por trabalhar com esta matriz.

\subsection{Potencialidades Educacionais Da Discussão Sobre Necessidades Humanas Essenciais}

Da forma defendida por Freire (2008), não se pode cobrar compromisso do ser que não tem conhecimento. Segundo Pais (1999), conhecimento diz respeito ao contexto mais individual e subjetivo, revelando aspectos com os quais o sujeito tem uma experiência mais direta e pessoal. Nesse contexto, ainda é possível distinguir o conhecimento racional e sensorial, adquiridos com base nos valores de uma cultura. Para Morin (2000), o conhecimento não é um espelho das coisas ou do mundo externo. Todas as percepções são ao mesmo tempo, traduções e reconstruções cerebrais com base em estímulos ou sinais captados e codificados pelos sentidos. A projeção de nossos desejos e medos e as perturbações mentais trazidas por nossas emoções multiplicam os riscos de erro. Dessa forma, ao propor os saberes necessários à educação do futuro, esse autor afirma que a educação não pode ser cega ao que é conhecimento humano, dificuldades e tendências ao erro e a ilusão.

Com relação à cultura e alguns valores, o psiquiatra Flavio Gikovate (2017), afirma que é possível fazer uma síntese do que tem sido o modo de pensar das gerações que nos antecederam: muitas de nossas peculiaridades foram catalogadas pela sociedade como indignas pela precária reflexão que temos produzido. Em geral nos mostram que podemos ser generosos, 
solidários, piedosos, preocupados com os outros, mas não se discute outras peculiaridades de nossa personalidade, como a inveja, a vaidade, a agressividade, entre outras. Não aprendemos a ter aceitação serena destas peculiaridades e não as estudamos para compreender os processos psíquicos que levam ao seu desenvolvimento. Assim, a percepção de nossas reais necessidades pode ser distorcida e não se pode buscar maneiras de manejar os efeitos desagradáveis observados. Dessa forma, pode-se afirmar que existe uma carência na formação para o autoconhecimento e para a autogestão.

Com base na concepção de conhecimento de Pais (1999) e no raciocínio do psiquiatra Gikovate (2017) e de Morin (2000) descritos, concluímos que conhecimento só não basta para minimizar comportamentos prejudiciais ao sujeito e à sociedade a qual pertence. Por exemplo, um adolescente pode embriagar-se mesmo conhecendo os efeitos deletérios do álcool. Faz-se necessário compreender os aspectos internos que nos limitam, como se manifestam e identificar a real necessidade não atendida. Por traz de um mal comportamento existe sempre uma necessidade não atendida, esclarecem Nelsen, Lott \& Glenn (2017). Ainda que não seja possível tudo decifrar, o que se defende é uma alfabetização emocional, um conhecimento geral destes aspectos de nossa personalidade para permitir reflexão maior que aquela que temos produzido e abrir um caminho para que o próprio sujeito tenha ferramentas para lidar melhor com aspectos negados de sua personalidade, com mais naturalidade. Nesse sentido, o neurologista Damásio (2000), afirma que às vezes usamos nossa mente para ocultar uma parte de nosso ser de outra parte de nosso ser. Esse encobrimento não é necessariamente intencional. No entanto, o caráter vago, intangível e difícil de definir das emoções e dos sentimentos provavelmente é um sintoma deste fato. Na maioria dos casos, em vez de concentrar nossos recursos em nossos estados interiores, nossa opção é considerar mais vantajoso concentrá-los nas imagens que descrevem problemas que ocorrem lá fora. No entanto, esse desvio de perspectiva em relação ao que está disponível em nossa mente tem seu custo. Tende a impedir a percepção da possível origem e natureza do que denominamos Self. Morin (2000), esclarece que nenhum dispositivo cerebral permite distinguir a alucinação da percepção, o imaginário do real, o subjetivo do objetivo, dado que recebemos muitos estímulos o tempo todo e só percebemos uma pequena parte deles. “As vias de entrada e saída do sistema neurocerebral, que colocam o organismo em conexão com o exterior, representam apenas $2 \%$ do conjunto, enquanto $98 \%$ referem-se ao funcionamento interno do organismo, (Morin, 2000, p.21)”. Assim, para esse autor, o egocentrismo, a necessidade de autojustificativa, a tendência de projetar sobre o outro a causa do mal que nos aflige, fazem com que cada um minta para si próprio sem detectar essa mentira 
da qual é o autor. O que permite a distinção entre o real e o imaginário é a atividade racional da mente, que apela para o controle do ambiente, recebendo resistência física do meio ao desejo e ao imaginário; para o controle da prática, como atividade verificadora; para o controle dos que estão próximos de nós, quando questiona: será que você vê o mesmo que eu? e para o controle cortical, ou seja, memórias e operações lógicas. De maneira geral é a racionalidade que é corretiva e poderá ser a melhor proteção contra o erro e a ilusão, explica (Morin, 2000).

Exemplificamos a seguir esse fato com a explanação de Gikovate (2017), sobre o perigo nos processos comparativos e sua relação com a não identificação da necessidade implícita nesse comportamento. Este autor esclarece que essa discussão não se aplica aos casos de graves desigualdades sociais e se refere aos nossos relacionamentos interpessoais.

A comparação que deriva da busca de significância relativa é um erro lógico, porque somos diferentes, temos diferentes tipos de inteligência, assim diferentes tipos de habilidades e não se pode comparar qualidades diferentes. A comparação é feita segundo algum código de valores estabelecido por um grupo social. Cada um se posiciona de maneiras diferentes frente a comparação, se sentindo ora superior a determinadas pessoas e ora inferior a outras. Ao se sentir superior, poderá experimentar piedade ou desprezo. Ao se sentir inferior, poderá sentir inveja, acompanhada ou não de agressividade. A única comparação saudável e propícia à melhora do nível de consciência nos termos de Damásio (2000), seria a de nós mesmos em momentos anteriores com os atuais. O tipo de reação agressiva mais comum que pode ser produzida com a comparação é a inveja. A inveja poderá acontecer como um desdobramento de tentativas de exercer uma atividade para a qual não se foi destinado.

A pessoa se vê humilhada diante de determinadas virtudes que observa no outro e gostaria de possuir. Ela se sente gravemente ferida na vaidade ou no orgulho, prejudicada e menos favorecida. Reage porque se sentiu ofendida pelo simples fato de o outro existir e ser como é. Tenta destruir as virtudes incômodas ou quem as tem. Procede assim para se vingar da sensação dolorosa de ter se sentido inferior, (Gikovate, 2017, p.47).

Fica claro, no discurso deste psiquiatra, que não reagimos somente às adversidades externas reais, mas também, ao que imaginamos e à maneira como interpretamos os fatos, eventualmente sem percepção clara do que nos move. É importante conhecer nossas fraquezas íntimas e minimizar as pressões que sofremos de fora para dentro. Quanto maior for nosso autoconhecimento, mais comando para a razão podemos transferir. Com o autoconhecimento, aumentamos nosso poder pessoal, a razão ganha elementos necessários para se sobrepor tanto aos impulsos quanto aos vários preconceitos que nos povoam contra nossa vontade, conclui (Gikovate, 2017). 
Este autor, afirma que os pais e professores não deveriam usar um dos filhos, alunos ou a si mesmos como exemplo a ser seguido. É mais útil contribuir para que descubram suas próprias potencialidades, no que foram ou não favorecidos pela natureza e que pode ser desenvolvido em si mesmos.

Sendo assim, a atividade proposta visa articular de maneira transdisciplinar emoções, sensações, sentimentos e aprendizado estatístico, para que os alunos possam observar, refletir e iniciar o aprendizado sobre necessidades humanas essenciais. Dessa maneira, o processo educacional poderá contemplar a melhora do funcionamento dos recursos mentais, para melhor atuação dos adolescentes em diferentes áreas de suas vidas.

\section{Procedimentos Metodológicos}

Propomos a integração da Estatística com as contribuições da Neurociência e Educação Socioemocional CASEL (2015) de maneira transdisciplinar, a fim de instigar nos estudantes uma visão cada vez mais completa da realidade em que vivem. Formar para um desenvolvimento humano comprometido com a melhora da sociedade, como propõe a legislação educacional, implica em educar para a complexidade, nos termos de Morin (2015). Complexo para este autor é o que está tecido junto e que a fragmentação do conhecimento disciplinar na escola não permite captar. Dessa forma, o objeto do ensino deve ser conhecer e lidar com a realidade e a finalidade da disciplina, neste contexto é estabelecer um vínculo entre conhecimento científico e realidade.

“As metodologias ativas dão ênfase ao papel protagonista do aluno, ao seu envolvimento direto, participativo e reflexivo em todas as etapas do processo, experimentando, desenhando, criando, com orientação do professor”, (Moran, 2018, p.4).

Dessa forma, o objetivo da atividade aqui descrita é trabalhar com um contexto instigante, capaz de capturar a atenção dos alunos, para que apreendam os conceitos previstos, seus significados, aplicações e não apenas os algoritmos e procedimentos de cálculo. Com o mesmo nível de importância, o contexto permitirá de maneira transdisciplinar, refletir sobre problemas que estão na base do endividamento pessoal: desejo de ser feliz e busca do atendimento dessa necessidade com atitudes inapropriadas para si e para a vida sustentável no planeta. Esta atividade foi aplicada a 23 alunos do $6^{\circ}$. ano da Educação Básica de uma escola privada da grande São Paulo, no primeiro semestre de 2018.

A elaboração da atividade foi orientada pelo roteiro que consta no Quadro 1, adaptado de 
Novaes (2015), para facilitar o trabalho dos professores na elaboração de atividades interdisciplinares ou transdisciplinares entre Estatística e Educação Socioemocional.

\section{Quadro 1. Roteiro para elaborar atividades interdisciplinares ou transdisciplinares}

I. Descrição do conteúdo do programa de ensino a ser abordado, ano/série.

II. Objetivo:

O desenvolvimento da atividade, se dará com o objetivo de considerar o processo de ensino e aprendizagem do conteúdo específico citado em I e simultaneamente favorecer a formação pessoal do estudante, com o mesmo nível de importância.

Cada atividade buscará contribuição com um ou mais objetivos da Educação Básica que constam no Art. 22 da LDB: preparar para o mundo do trabalho; para a cidadania/vida; para o aprendizado permanente e para estudos posteriores.

III. Escolha do Tema:

O que norteará a escolha do tema é uma educação afinada com a qualidade de vida dos estudantes, que pode ser voltada a contribuições para: Saúde física, Saúde emocional, Saúde Financeira, Bem-estar social, Saúde ambiental, Saúde planetária, e outros temas considerados pertinentes.

IV. Escolha do contexto para desenvolvimento do tema:

De maneira transdisciplinar o contexto escolhido, favorece o desenvolvimento do conteúdo específico de Estatística e a formação pessoal do educando. A escolha do contexto pode ser facilitada pelo conhecimento dos alunos e de suas características (SHULMAN, 2005).

V. Descrição da atividade/situação problema.

Descrever detalhadamente a proposta da atividade ou situação problema e a solução esperada. Caso possa haver mais de uma solução adequada para a situação proposta, estabelecer essa discussão.

VI. Descrição das aprendizagens favorecidas com a atividade.

Descrever as possibilidades de aprendizagens de conteúdo específico e de formação pessoal, que podem ser tratadas naquele contexto, com as escolhas estabelecidas.

VII. O aluno é principal ator e o professor é mediador.

Trabalhar preferencialmente em grupo, instigar os alunos para que possam falar, refletir e agir por iniciativa própria.

VIII. Toda análise estatística envolvida na situação proposta ocorre segundo os princípios da Análise Exploratória de dados, segundo (Batanero, et all, 1991).

IX. A atividade pode ser finalizada com uma roda de conversa, (Pizzimenti, 2013).

O disparador para a roda de conversa pode ser a análise e discussão da atividade elaborada, enriquecida de um texto de leitura complementar sobre o contexto trabalhado, uma música, poesia, filme, improvisação teatral, entre outras escolhas. A roda de conversa complementa a Análise Exploratória dos dados. (Batanero, 2001).

Fonte: Adaptado de (Novaes, 2015).

Consta no plano de ensino destes alunos, no que se refere à Estatística: porcentagem, leitura e interpretação de gráficos e tabelas. Os alunos foram colocados em situação de ação para que pudessem atuar por conta própria e somente quando surgiam dúvidas o professor atuava para que pudessem avançar na atividade. Por exemplo, no decorrer da atividade os alunos não souberam o que fazer com as casas decimais que apareceram quando calcularam as frequências relativas, então, a professora discutiu um critério de arredondamento. Foi discutido, os tipos de variáveis estatísticas, que não consta no plano, mas se apresentou como necessário para elaboração de gráficos adequados, leituras e interpretações solicitadas. A descrição da atividade proposta consta no quadro 2 que segue. 
Quadro 2: Descrição da Atividade proposta aos alunos do $6^{\circ}$. ano.

\begin{tabular}{|c|}
\hline Primeira etapa \\
\hline 1. Fazer um desenho e elaborar uma frase sobre o que é felicidade para você. \\
\hline 2. Responder individualmente: Quais são as 10 coisas que você considera mais importantes para ser feliz? \\
\hline $\begin{array}{l}\text { 3. Reunir-se em grupos para resumir, apresentar e discutir os dados obtidos nos grupos e em seguida na } \\
\text { classe, para a questão } 1 \text {. }\end{array}$ \\
\hline $\begin{array}{l}\text { 4. Com postura de pesquisador, solicite aos seus familiares que respondam à questão } 1 \text { e em seguida } \\
\text { proceda como solicitado no item } 2 \text {. }\end{array}$ \\
\hline Segunda etapa da atividade \\
\hline $\begin{array}{l}\text { 1. Comparar os resultados obtidos com a matriz de necessidades humanas essenciais (Max-Neef; Hopenhayen } \\
\text { apud O'Sullivan, } 2004 \text {, p. 348-353)*. }\end{array}$ \\
\hline 2. Leitura do texto orientador para a comparação com a matriz das necessidades humanas essenciais. \\
\hline $\begin{array}{l}\text { 3. Roda de conversa com a participação da professora de ciências que estava abordando desenvolvimento } \\
\text { sustentável em suas aulas. }\end{array}$ \\
\hline 4. Apresentar e discutir os resultados da pesquisa com os familiares participantes. \\
\hline $\begin{array}{l}\text { * Matriz de necessidades humanas essenciais e maneiras de satisfazê-las, apresenta quatro } \\
\text { necessidade na categoria existencial: ser, ter, fazer e interagir e nove necessidades na categoria axiológica: } \\
\text { subsistência, proteção, afeto, compreensão, participação, ócio, criação, identidade e liberdade. No corpo da } \\
\text { matriz constam maneiras possíveis de satisfazer essas necessidades interdependentes. Os autores explicam que } \\
\text { a melhor forma de ver as necessidades humanas é como um sistema no qual todas estejam inter-relacionadas e } \\
\text { sejam interativas. A satisfação das necessidades opera como simultaneidades, complementariedades e } \\
\text { equilíbrios e a falta de qualquer uma delas pode gerar patologias. O’Sullivan (2004) utiliza esse modelo não } \\
\text { como uma formulação definitiva, mas para ampliar nossa noção de qualidade de vida. }\end{array}$ \\
\hline
\end{tabular}

\section{Fonte: As autoras}

Exemplificamos no quadro 3, uma parte desta matriz com as quatro necessidades segundo as categorias existenciais e três das nove necessidades segundo as categorias axiológicas.

Quadro 3: Algumas categorias da Matriz de necessidades humanas

\begin{tabular}{|c|c|c|c|c|}
\hline \multirow{2}{*}{$\begin{array}{c}\text { As } \\
\text { necessidades } \\
\text { segundo } \\
\text { categorias } \\
\text { axiológicas }\end{array}$} & \multicolumn{4}{|c|}{ As necessidades segundo categorias existenciais } \\
\hline & Ser & Ter & \multirow{2}{*}{\begin{tabular}{|l|}
\multicolumn{1}{|c|}{ Fazer } \\
Alimentar-se, \\
procriar-se, \\
descansar, \\
trabalhar
\end{tabular}} & Interagir \\
\hline Subsistência & $\begin{array}{l}\text { Saúde física, saúde } \\
\text { mental, equilíbrio, } \\
\text { senso de humor, } \\
\text { adaptabilidade }\end{array}$ & $\begin{array}{l}\text { Alimento, abrigo e } \\
\text { trabalho }\end{array}$ & & $\begin{array}{ll}\text { Meio } & \text { ambiente } \\
\text { vivo, } & \text { ambiente } \\
\text { social } & \end{array}$ \\
\hline Afeto & $\begin{array}{l}\text { Autoestima, } \\
\text { solidariedade, respeito, } \\
\text { tolerância, } \\
\text { generosidade, } \\
\text { reciprocidade, } \\
\text { senso de humor }\end{array}$ & \begin{tabular}{|l|} 
Amizades, \\
família, \\
parcerias, \\
relações com a \\
natureza.
\end{tabular} & $\begin{array}{l}\text { Carícias, expressar } \\
\text { emoções, partilhar, } \\
\text { cuidar dos outros, }\end{array}$ & $\begin{array}{l}\text { Privacidade, } \\
\text { intimidade, } \\
\text { lar, } \\
\text { espaço de interação }\end{array}$ \\
\hline Identidade & $\begin{array}{l}\text { Sensação de fazer parte } \\
\text { de algo maior, } \\
\text { consistência, } \\
\text { diferenciação, } \\
\text { autoestima, } \\
\text { assertividade }\end{array}$ & $\begin{array}{|lr|}\text { Símbolos, } & \text { linguagem, } \\
\text { religião, } & \text { hábitos, } \\
\text { costumes, grupos de } \\
\text { referência, valores, } \\
\text { normas, remória } \\
\text { histórica, trabalho }\end{array}$ & $\begin{array}{l}\text { Comprometer-se, } \\
\text { integrar-se, } \\
\text { enfrentar, tomar } \\
\text { decisões, conhecer- } \\
\text { se, reconhecer-se, } \\
\text { realizar-se, }\end{array}$ & $\begin{array}{lr}\text { Ritmos } & \text { sociais, } \\
\text { ambientes } & \text { dos } \\
\text { quais a pessoa } & \text { faz } \\
\text { parte, } & \\
\text { estágios } & \text { de } \\
\text { maturação } & \end{array}$ \\
\hline
\end{tabular}

Fonte: adaptação de (Max-Neef e Hopenhayen apud O’Sullivan, 2004, p. 348-353)*. das autoras. 


\subsection{Aprendizagens supostamente favorecidas com a atividade}

Conforme o item VI do roteiro do quadro 1 descrevemos as aprendizagens que supomos ser favorecidas com esta atividade, são as que seguem:

$>$ Desenvolvimento dos temas de Estatística descritos no plano do curso, de maneira significativa para que os alunos apreendam os conceitos e aplicações, não apenas algoritmos. Permitir aos estudantes vivenciarem todas as etapas de uma pesquisa - da coleta de dados à apresentação e discussão dos resultados.

Trabalhar com os alunos em grupo para que em situação de ação, tenham a oportunidade de participar, expressar livremente suas opiniões, ouvir e respeitar a opinião dos colegas. Receber ajuda dos demais se necessário. Contribuir para o preparo para o mundo do trabalho, onde é necessário saber trabalhar em grupo.

$>$ Com base nas necessidades humanas essenciais, instigar a reflexão sobre a diferença entre consumo e consumismo, necessidade e maneira de satisfazer uma necessidade de um lado e de outro lado, noção de suficiência mediante consequências no nível pessoal e ambiental. Envolvimento da família na reflexão elaborada pelos alunos, para potencializar o aprendizado socioemocional.

$>$ Solicitar aos alunos a postura de pesquisador para entrevistar os familiares, implica em ouvilos sem emitir opinião e fornecê-las somente no momento da discussão. Assim, se pode trabalhar a capacidade de ouvir e respeitar o outro e se manifestar no momento apropriado. Como discutido anteriormente, os jovens podem ser impulsivos e ter dificuldade para saber esperar e coordenar prioridades. Contribuir para o amadurecimento das funções executivas cerebrais dos adolescentes.

$>$ Roda de conversa como metodologia de ensino, para complementar a análise dos dados estatísticos, contribui para a Análise Exploratória de Dados, Batanero (2001) e aprendizagens socioemocionais permitidas com a situação proposta. Permitirá ao jovem se expressar livremente e aprender a esperar a sua vez para falar. Contribuir para o controle da impulsividade e respeito à inteligência dos colegas, ao notar que eles podem ter coisas importantes para dizer.

Após a aplicação da atividade observamos se estas ou outras aprendizagens de fato ocorreram ou foram favorecidas. 


\section{Análise dos Resultados}

Com relação aos aspectos estatísticos, para entrevistar os familiares, os alunos relataram que foi difícil não emitir opinião, mas cumpriram e gostaram de estar no papel de pesquisador. Exercitaram a capacidade de ouvir e respeitar o outro, se manifestando apenas no momento apropriado, ou seja, no momento da análise dos dados na roda de conversa. Como discutido anteriormente, os jovens são impulsivos, têm dificuldade para saber esperar e coordenar prioridades. Macedo \& Bressan (2014), afirmam que as áreas corticais relacionadas ao controle de impulsos ainda não estão suficientemente maduras e necessitam de ajuda externa para completar esse amadurecimento. Assim, representar o papel de pesquisador, com a descrição das responsabilidades para a função, contribuiu para o amadurecimento das funções executivas superiores destes adolescentes.

Utilizaram calculadora para o cálculo das porcentagens e surgiu a necessidade de discutir critério de arredondamento, pois os alunos não souberam o que fazer com os valores que não eram exatos. Os gráficos foram feitos na aula de desenho geométrico e foi necessário discutir escala e variáveis estatística. Considerando as dez necessidades citadas com maior porcentagem e as menos citadas, foi discutido valores atípicos e decidido considerar todas as necessidades na análise, pois um dos objetivos da pesquisa era verificar se o grupo reconhecia como necessidades humanas fundamentais, todas citadas na matriz e discutir o esquecimento de alguma, se houvesse.

Na primeira etapa da atividade, os alunos esboçaram gráficos e tabelas, inicialmente com orientações da professora. Duas alunas foram eleitas para liderar a elaboração das tabelas e gráficos que reunia os dados da classe. As representações dos familiares, elaboraram sem ajuda da professora, como na Figura 1.

Com relação ao aspecto socioemocional, nota-se nos relatos dos alunos, que o envolvimento da família foi importante e gratificante para todos os envolvidos:

Aluno A. Fiquei surpresa com as respostas de meus colegas não pensei que iam colocar o mesmo que eu. Não fiquei surpresa com as respostas de meus pais sabia que não ia ser respostas rápidas.

Aluno B. A parte que mais gostei, foi entrevistar meus pais, causou um clima diferente dentro de casa. Aluna C. Professora, houve evolução no pensamento e no aprendizado.

Aluna D. Achava que ia ser veterinária, mas agora estou vendo que quero ser pesquisadora.

Aluna E. Fiquei feliz quando pesquisei meu avô e ele respondeu: ficar com meus netos. Nunca pensei que isso era importante para ele. 


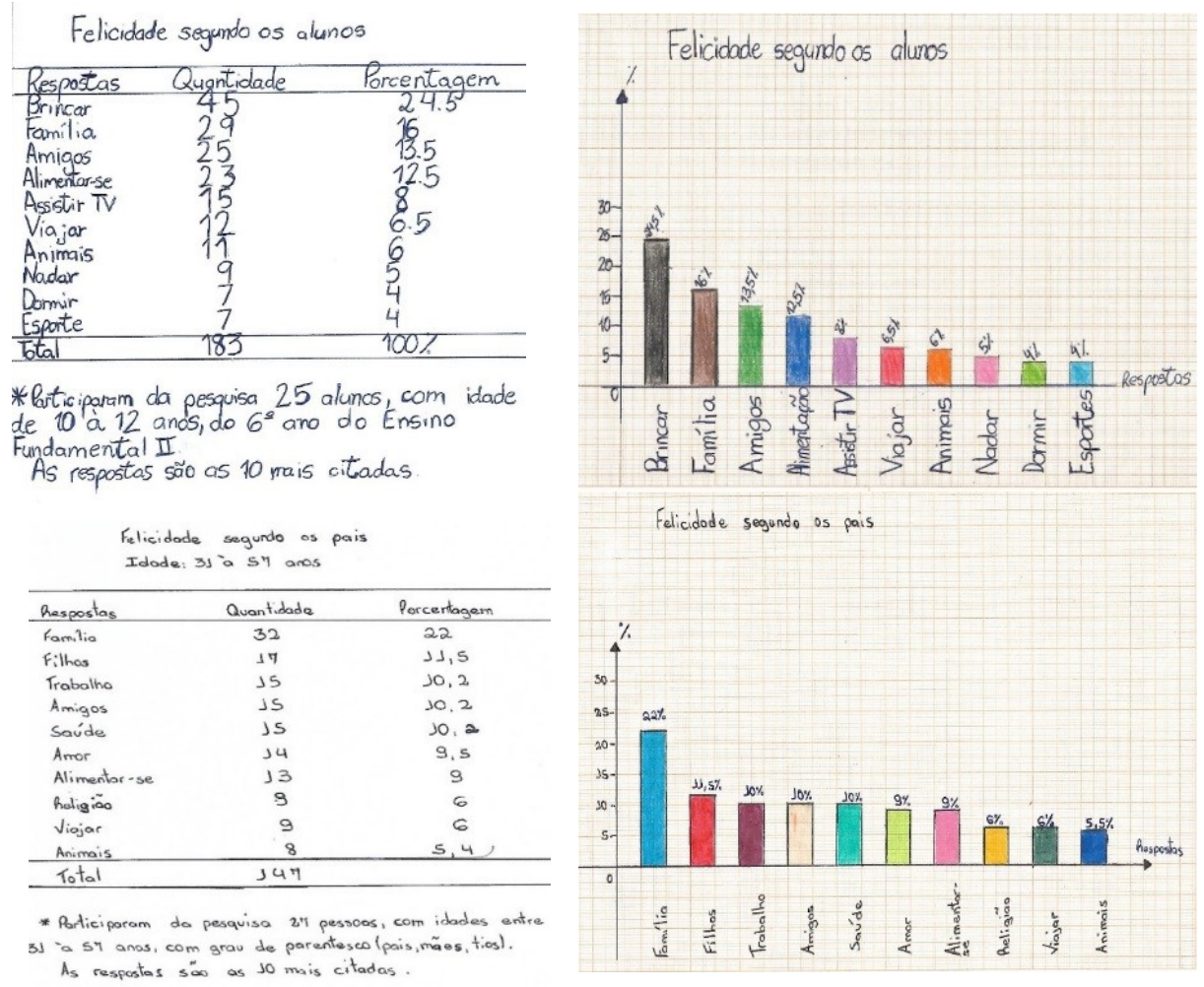

Figura 1: Felicidade segundo os alunos e seus familiares Fonte: Atividades realizadas pelos alunos do $6^{\circ}$ ano.

Mostraram-se surpresos e felizes quando seus avós afirmaram, estar junto com seus netos como uma das coisas que os faziam felizes. Esse fato não era óbvio na percepção da criança e evidencia a importância da comunicação para percepção da realidade, que denota satisfação da necessidade essencial de afeto. Citaram atividades de Lazer, determinado tipo de comida, família, amigos e dormir, prioritariamente associadas a maneiras de satisfazer as necessidades de subsistência que conduzem a bens tangíveis. Os pais e os avós, como se observa no gráfico, citaram prioritariamente família, filhos, trabalho, amigos, saúde, amor, respeito, fé, mais associadas à satisfação de necessidades que conduzem à obtenção de bens intangíveis. Esse fato propiciou para os alunos um contraste significante em relação ao que foi anotado por eles, marcando o início da reflexão sobre esse tema e a percepção e valorização de bens intangíveis como necessidade.

Prof. Vocês notaram diferenças entre o que vocês citaram e seus familiares?

Aluno $\boldsymbol{F}$. Eles falaram coisas sérias.

Aluno G. Alimentar-se pra nós é comer besteiras, pra minha mãe é brócolis...

Prof. Chocolate é importante ou fundamental?

Aluno G. Importante, não morre se ficar sem.

Prof. Mas se é importante como faz então?

Aluno H. Come pouco, chocolate e brócolis.

Prof. Acho que ele quer dizer equilibrio... 
A citação de determinado tipo de comida, como chocolate na categoria alimentar-se descrita no gráfico, como uma das coisas mais importante para ser feliz, deu margem para a discussão sobre necessidade e diferentes maneiras de satisfazer uma necessidade. Nesse caso a necessidade essencial é alimentação e existem muitas formas de estar bem alimentado. Permitiu refletir sobre o que é consumo e consumismo, o que é importante e o que é fundamental em nosso meio social, como por exemplo, consumo de bens acima da capacidade de renovação da matéria prima utilizada na produção destes bens. Com a participação da professora de Ciências, foi discutido princípios do consumidor consciente.

Vale ressaltar que os pesquisados não apresentaram percepção de algumas necessidades descritas na matriz, tais como, direitos, responsabilidades e deveres como necessidades fundamentais, mas foram reconhecidas como tal na discussão ocorrida na roda de conversa.

Estabelecendo uma reflexão sobre os processos comparativos discutidos e a matriz de necessidades, pode-se notar que a não percepção de algumas necessidades essenciais poderiam provocar enganos que conduzem ao tratamento equivocado, como descrito por Gikovate (2017). A necessidade de identidade e de fazer parte de um grupo aparece quando o aluno A, se sente surpreso com o número de necessidades citadas pelos colegas iguais às suas. A necessidade essencial, não é necessariamente repetir o comportamento dos pares, mas sentir-se incluído, respeitado e pertencente a um grupo. Dessa forma, promover adaptabilidade, ser visto e sentir o respeito dos demais por aquilo que se é. Para esta percepção faz-se necessário o atendimento da necessidade de compreensão para interagir com os outros e consigo mesmo. Note que alguns estudantes não tinham a percepção da importância que tinham para os seus avós, o que reduz a percepção do afeto e estima que recebem.

A roda de conversa proposta, permitiu do ponto de vista da Educação Estatística, adequada Análise exploratória dos dados e do ponto de vista socioemocional, que todos fossem vistos, respeitados e tivessem voz. Contribuiu ainda, para dissolver naturalmente sentimentos de desagrado não manifestados pelos jovens. Notamos que o diálogo com as premissas da roda de conversa, ou seja, descrevendo os fatos como são, sem julgamentos e críticas, favoreceu a emergência da inteligência coletiva, para percepção de fragilidades de cada participante. As manifestações de líderes positivos revelou aspectos de características pessoais que favorecem o autoconhecimento, apenas por ter a oportunidade de interagir com o grupo. Esta atividade permitiu trabalhar o autoconhecimento associado à consciência social.

Utilizando a Análise Exploratória de Dados, Batanero (2001) e os conhecimentos 
divulgados sobre a neurociência e educação, vemos nesta matriz, um grande potencial para elaborar diferentes atividades, discutindo apenas uma necessidade essencial em especial ou um grupo conveniente delas.

\section{Considerações Finais}

Os alunos se envolveram com a atividade descrita no Quadro 2, houve muitas manifestações sobre o desejo de realizar outras atividades semelhantes. Portanto o nosso objetivo de apresentar uma atividade instigante que capturasse a atenção dos alunos, foi atendido.

Trabalhamos os conceitos estatísticos propostos no plano e simultaneamente, potencializamos a comunicação entre familiares e estabelecemos uma reflexão com todos, sobre uma concepção do que é necessidade humana essencial e consumo consciente, frente aos recursos naturais de que dispomos. Assim, esta atividade contribuiu para despertar a atenção e a percepção para estas questões, o que abre portas para a melhoria da capacidade de fazer escolhas para o atendimento de nossas necessidades, articuladas com as necessidades de outros, de nossa espécie e do planeta.

O currículo da Educação Básica, especialmente na escola pública, da forma como está organizado em conteúdos e disciplinas, dificulta a inclusão de mais uma disciplina que se dedique à discussão aqui estabelecida, como sugere uma das abordagens da educação socioemocional CASEL (2015). Dessa forma, unimos nas atividades propostas os estudos científicos disponibilizados pelos profissionais da área médica com nossos conhecimentos pedagógicos, bem como, com as ferramentas de análise em Estatística para busca de um espaço no currículo escolar, para de maneira transdisciplinar contribuir com o "sair à luz", metáfora de Damásio (2000) para a mente conhecedora. Novaes (2019), descreve como outros professores de outras disciplinas, desenvolvem trabalhos semelhantes e as justificativas daqueles que não desenvolvem, como por exemplo, falta de formação para esta atuação. Esperamos, com este trabalho, motivar esses últimos.

\section{Referências}

Andrews, S. (2011). A Ciência de Ser Feliz. São Paulo, Editora Ágora.

Batanero, C.; Estepa, A.; Godino, J. D. (1991). Análisis exploratório de datos: sus possibilidades en de la enseñaza secundaria. Suma, $\mathrm{n}^{0}$ 9, 1991: 25-31. 
Bem-Shahar, T. (2018). Seja mais feliz: aprenda a ver alegria nas pequenas coisas para uma satisfação permanente. Tradução Paulo Anthero S. Barbosa. São Paulo: Planeta Brasil.

Berndt, C. (2018). Resiliência: o segredo da força psíquica. Tradução de Markus A. Hedger. Petrópolis, Rj: vozes.

Brasil. Lei de Diretrizes e Bases da Educação Nacional. Lei número 9394/1996.

Ministério da Educação. Secretaria da Educação Básica. Diretrizes Curriculares Nacionais para a Educação Básica. Brasília: MEC/SEB, 2013.

Casel (2015). Collaborative for Academic, Social, and Emotional Learning. Effective social and emotional Learning Programs: Middle and High Sxhool Edition. Chicago.

Cosenza, R M.; Guerra, L. B. (2011). Neurociência e Educação: como o cérebro aprende. Porto Alegre: Artmed.

Damásio, A. (2000). O mistério da consciência: do corpo e das emoções ao conhecimento de si. Tradução: Laura Teixeira Mota. São Paulo: Compahia das Letras.

Freire, P. (2008). Educação e Mudança. Tradução de Moacir Gadotti e Lilian L. Martins. Rio de Janeiro: Paz e Terra.

Gal, I. (2002). Conocimientos básicos de estadística en adultos: significados, componentes, responsabilidades. Revista Internacional de Estatística (Haifa, Israel), 70(1), 1-25.

Gikovate, F. (2017). A liberdade possível. São Paulo: MG Editores.

Lent, R. (2016). Neurociência da mente e do comportamento. Rio de Janeiro: Guanabara Koogan.

Macedo, L.; Bressan, R. A. (2016). Desafios da Aprendizagem: como as neurociências podem ajudar pais e professores. Campinas, SP.: Papirus 7 Mares.

Moraes, M. C.; Torre, S. (2004). Sentipensar: fundamentos e estratégias para reencantar a educação. Petrópolis - RJ: Vozes.

Moore, D. S. (2005). A Estatística Básica e sua prática. 3a . edição. Tradução: Cristina F. C. Pessoa. Rio de Janeiro: LTC.

Moran, J.(2004). Metodologias ativas para uma aprendizagem mais profunda. IN: BACICH, L; MORAN, J. (orgs). Metodologias ativas para uma educação inovadora. Porto Alegre: Penso.

Morin, E (2000). Os sete saberes necessários à Educação do futuro. São Paulo: Cortez; Brasília, DF: UNESCO.

Morin, E. (2011). O método 6: ética. Porto Alegre: Sulina.

Morin, E. (2015). Introdução ao pensamento complexo. Porto Alegre: Sulina. 
Mussack, E. (2003). Metacompetência: uma nova visão do trabalho e da realização pessoal. São Paulo: Editora Gente.

Nelsen, J; Lott, L.; Glenn, H. S. (2017). Disciplina positiva em sala de aula: como desenvolver o respeito mútuo, a cooperação e a responsabilidade em sua sala de aula. Tradução de Bete P. Rodrigues e Fernanda Lee. Barueri - SP: Menole.

Novaes, D. V. (2015). Educação para a qualidade de vida: contribuições da Educação Estatística. International Association for Statistical Education (IASE - Satellite Conference). Rio Janeiro, 22-24 July 2015.

Novaes, D. V. (2019). Currículo, legislação e prática em políticas de ações afirmativas e sustentabilidade: uma abordagem para Educação Socioemocional. Curitiba: CRV.

O’Sullivan, E. (2014). Aprendizagem transformadora: uma visão educacional para o século XXI. São Paulo: Cortez.

Pais, L. C. (2012). Transposição Didática. IN: MACHADO, S. D. A. (org.). Educação Matemática: uma nova introdução. São Paulo: Educ, p. 11- 48.

Pizzimenti, C. (2013). Trabalhando valores em sala de aula: histórias para rodas de conversas. Petrópolis: Vozes.

Shulman, L. S. (2005). Conocimiento y enseñanza: fundamentos de la nueva reforma: 1. Revista de Currículum y Formación del Profesorado, 9(2), 1-30.

Tacla, C.; Norgren, M. B.; Ferreira, L.S.P.; Estanislau, G.M.; Fóz, A. (2014). Aprendizagem sociemocional na escola. In: ESTANISLAU, G.M.; BRESSAN, R.A. (Orgs.). Saúde mental na escola: o que os educadores devem saber? Porto Alegre: Artmed, p. 48-62.

Wong, R. (2009). Menos razão e mais inspiração. Revista CIO, 23, 16-19.

Submetido em: 30/03/2019

Aceito em: 06/09/2019 